\title{
Intercellular Adhesion Molecule 1 Functions as an Efferocytosis Receptor in Inflammatory Macrophages
}

Hannah L. Wiesolek, ${ }^{*}$ Triet M. Bui, ${ }^{*}$ Joseph J. Lee, ${ }^{*}$ Prarthana Dalal, ${ }^{*}$ Ariel Finkielsztein, ${ }^{*}$ Ayush Batra, ${ }^{\dagger}$ Edward B. Thorp, * and Ronen Sumagin*

From the Department of Pathology, * and the Ken \& Ruth Davee Department of Neurology, ${ }^{\dagger}$ Northwestern University Feinberg School of Medicine, Chicago, Illinois

Accepted for publication

December 19, 2019.

Address correspondence to Ronen Sumagin, Ph.D., Department of Pathology, Northwestern University Feinberg School of Medicine, 300 East Superior St., Chicago, IL 60611. E-mail: ronen.sumagin@northwestern. edu.

Intercellular adhesion molecule-1 (ICAM-1) is a transmembrane glycoprotein with five extracellular IgG-like domains involved in cell-to-cell binding and a short cytoplasmic tail that is anchored to the cell cytoskeleton and can facilitate outside-in signaling. ${ }^{1,2}$ ICAM-1 has low basal expression, but is markedly up-regulated by several principal cell types participating in inflammatory responses, including endothelial, epithelial, and some immune cells. ${ }^{3-6}$

ICAM-1 fulfills several critical functions in the vascular endothelium both in healthy and inflamed tissue. It is best known for its role in regulating leukocyte adhesion and extravasation events through binding interactions with leukocyte $\beta 2$-integrins. ${ }^{6-9}$ In addition to mediating adhesive interactions, it also has been shown to regulate endothelial cell shape and vascular barrier function by controlling protein kinase $\mathrm{C}$, proto-oncogene tyrosine-protein kinase Src activity, and intracellular calcium signaling. ${ }^{7,10,11}$ ICAM-1 expression is also increased markedly in epithelial cells during inflammation. Interestingly, in intestinal epithelial cells, increased ICAM-1 levels were linked to increased neutrophil [polymorphonuclear leukocyte (PMN)] retention at the luminal surface, and have been implicated in regulating intestinal permeability ${ }^{5}$ and wound healing. ${ }^{12,13}$

Supported by NIH grant DK116663NIH, the Digestive Health Foundation, an American Cancer Society Research Scholar Award, and a Crohn's and Colitis Foundation Senior Research Award.

Disclosures: None declared. 
ICAM-1 is expressed by immune cells, and its contributions to immune cell effector function is being recognized increasingly. For example, ICAM-1 expressed by dendritic or natural killer cells is important for T-lymphocyte binding and the formation of immune synapses. ${ }^{14}$ ICAM-1 expressed by $\mathrm{T}$ lymphocytes can deliver a costimulatory signal, which is required for T-cell activation, ${ }^{15}$ as well as contribute to programming the sensitivity of memory CD8 T cells to secondary stimuli. ${ }^{16}$ Recently, ICAM-1 expression was documented in PMNs also, where it contributed to their phagocytic function $^{17}$ and was associated with increased PMN longevity. ${ }^{18}$ Induction of ICAM-1 expression upon lipopolysaccharide (LPS) treatment has also been noted in macrophages, and was proposed to mark macrophage activation. ${ }^{19}$ Several recent studies have also implicated ICAM-1 in the regulation of macrophage polarization; however, with seemingly opposing function. For example, although ICAM-1-deficient macrophages in the tumor microenvironment were found to preferentially polarize toward the resident phenotype,$^{20}$ ICAM-1 deletion in inflamed lung led to polarization toward the inflammatory macrophage phenotype. ${ }^{21}$

One of the key functions of professional phagocytes such as macrophages is to remove apoptotic/necrotic cells through a specialized phagocytic process termed efferocytosis. To initiate efferocytosis, macrophages recognize specific changes on the cell surface of apoptotic cells (ACs), which distinguish them from viable cells. This includes the exposure of the plasma membrane inner leaflet phospholipid phosphatidylserine and deposition of complement. ${ }^{22}$ Coupling of ACs to macrophages is mediated by distinct efferocytotic receptors including the TAM (TYRO, AXL, MER) family of receptor tyrosine kinases, $\alpha \mathrm{V} \beta 3 / 5$ integrins, and CD36. ${ }^{23-25}$ Macrophage-AC interactions are facilitated further by several bridge molecules such as growth arrest specific 6, milk fat globule epidermal growth factorfactor 8, and thrombospondin. , $26,27^{\text {In addition to }}$ relieving tissue congestion, efferocytosis also leads to cellular reprogramming in newly recruited inflammatory macrophages, suppressing production of inflammatory and increasing production of proresolution cytokines, such as IL-10, transforming growth factor $\beta$, and prostaglandin E2. ${ }^{28-30}$ Thus, efferocytosis is an important component of homeostatic maintenance in healthy tissue and is a critical step for timely resolution of inflammation and successful wound healing. 25,31

Although many key players and signaling events mediating this process have been defined, efforts are still ongoing to identify new molecules that can be targeted to regulate efferocytosis with the goal of improving the resolution of inflammation. Here, we examined how expression patterns of ICAM-1 vary with noninflammatory and inflammatory macrophage polarization, and found that ICAM-1 expression was induced with inflammatory stimulation. ICAM-1 on inflammatory macrophages was found to contribute to efferocytosis by facilitating AC binding to macrophages. Thus, our studies identify a new role for ICAM-1 in macrophage function with potentially significant implications for inflammation resolution and tissue healing.

\section{Materials and Methods}

\section{Animals}

C57BL6J, ICAM-1 knockout (KO) mice (B6.129S4-

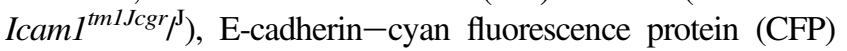
$\left[\mathrm{B} 6.129 \mathrm{P} 2(\mathrm{Cg})-\mathrm{Cdh} 1^{\mathrm{tm} 1 \mathrm{Cle} / \mathrm{J}}\right]$, and CX3CR1-green fluorecence protein (GFP) [B6.129P2(Cg)-Cx3cr1 $\left.{ }^{\mathrm{tm} 1 \mathrm{Litt} / \mathrm{J}}\right)$ ] mice were purchased from Jackson Laboratories (Bar Harbor, ME) and were maintained under specific pathogen-free conditions at Northwestern University, Feinberg School of Medicine animal facilities. Mice, aged 12 to 16 weeks, were used in all experimental protocols that were approved by the Institutional Animal Care and Use Committee.

\section{Cells}

Human monocytic cell line THP-1 and human peripheral blood T-cell line Jurkat (clone E6-1) were obtained from ATCC (Manassas, VA) and maintained in RPMI 1640 medium, supplemented with $10 \%$ fetal calf serum, $1 \% \mathrm{~L}$-glutamine, and 0.05 $\mathrm{mmol} / \mathrm{L}$ 2-mercaptoethanol as previously described. ${ }^{32,33}$ THP1 cells were differentiated using phorbol 12-myristate 13-acetate (PMA; $100 \mathrm{nmol} / \mathrm{L}$ ) for 5 days before use.

Mouse bone marrow (BM)-derived macrophages were isolated as previously described. ${ }^{34}$ Briefly, BM cells were flushed from the femur and tibia with serum-free Dulbecco modified Eagle's medium, and red blood cells were lysed by sequential treatment with $0.02 \%$ and $1.6 \% \mathrm{NaCl}$. Cells were plated at $6 \times 10^{6}$ cells per $10 \mathrm{~cm}$ nontissue culture-treated dish and differentiated into macrophages by adding $1 \times 10^{4}$ $\mathrm{U} / \mathrm{mL}$ macrophage colony-stimulating factor into the growth media. On day 6, macrophages were replated into 12-well plates and stimulated with either LPS/interferon- $\gamma$ (IFN $\gamma$ ) $\left(\mathrm{M} \phi_{\mathrm{IFN} \gamma / \mathrm{LPS}}, 50\right.$ and $20 \mathrm{ng} / \mathrm{mL}$, respectively) or IL-4 (M $\phi_{\mathrm{IL}-4}$, $20 \mathrm{ng} / \mathrm{mL}$ ) for 24 hours for acquisition of inflammatory and resident phenotypes, respectively. Primary human macrophages were differentiated from peripheral blood mononuclear cell-derived monocytes by culturing for 7 days in RPMI 1640 (10\% human serum) in the presence of macrophage colony-stimulating factor as previously described. ${ }^{35}$ Differentiated macrophages were stimulated with IFN $\gamma / \mathrm{LPS}$ ( 20 and $10 \mathrm{ng} / \mathrm{mL}$, respectively) before use in experiments. Mouse BM-derived PMNs were isolated and enriched to approximately $85 \%$ to $90 \%$ purity using Histopaque gradients (1077 and 1119; Sigma-Aldrich, St. Louis, MO) as previously described. ${ }^{36,37}$

\section{Reagents and Antibodies}

RPMI 1640 and Dulbecco modified Eagle's medium growth media, L-glutamine, penicillin, streptomycin, and nonessential amino acids were obtained from Cellgro (Manassas, 
VA). Fetal calf serum was obtained from Atlanta Biologicals (Atlanta, GA). N-formyl-l-methionyl-leucyl-Lphenylalanine, PMA, Hanks balanced salt solution with $\mathrm{Ca}^{2+}$ and $\mathrm{Mg}^{2+}$ (Hank balanced salt solution+) and Hank balanced salt solution without $\mathrm{Ca}^{2+}$ and $\mathrm{Mg}^{2+}$ (Hank balanced salt solution-), and tumor necrosis factor $\alpha$ (TNF $\alpha)$ were from Sigma-Aldrich. Human/murine IFN $\gamma$ and IL-4 were from PeproTech (Rocky Hill, NJ). Macrophage colony-stimulating factor was from e-Bioscience (San Diego, CA), and Jasplakinolide was purchased from Calbiochem (Burlington, MA). Calcein AM $(1000 \times)$ was purchased from BioLegend (San Diego, CA). Human/ mouse control and ICAM-1 siRNA was from Dharmacon (Laffyette, CO). OptiMEM and Lipofectamine 3000 were purchased from Thermo Fisher Scientific (Waltham, MA).

An anti-mouse ICAM-1 (YN1/1.7.4) purified or conjugated to fluorescein isothiocyanate, anti-CD64-PE, and fluorescein isothiocyanate-conjugated IgG control monoclonal antibodies were purchased from BD Biosciences (San Jose, CA), anti-human ICAM-1 (15.2) was purchased from Serotec (Raleigh, NC), major histocompitibility complex II (MHCII; M5/114.15.2) was purchased from BioLegend, horseradishperoxidase-conjugated anti-mouse and anti-rabbit IgGs were purchased from Jackson Immunoresearch (West Grove, PA), mouse anti-glyceraldehyde-3-phosphate dehydrogenase (FF26A/F9) was purchased from BioLegend, human antiglyceraldehyde-3-phosphate dehydrogenase was purchased from Sigma-Aldrich, and anti-mouse-Alexa 488 was purchased from Life Technologies (Waltham, MA).

\section{Efferocytosis Assay}

To induce apoptosis, Jurkat cells or BM-derived PMNs were stained with $1000 \times$ Calcein $\mathrm{AM}\left(20\right.$ minutes, $37^{\circ} \mathrm{C}$ in RPMI 1640, 10\% fetal bovine serum, 1\% HEPES, $1 \%$ penicillin, and $1 \%$ L-glutamine), irradiated (UV lamp, 7 minutes), and incubated for 2 hours at $37^{\circ} \mathrm{C}$. Approximately $75 \%$ apoptosis was confirmed by flow cytometry using
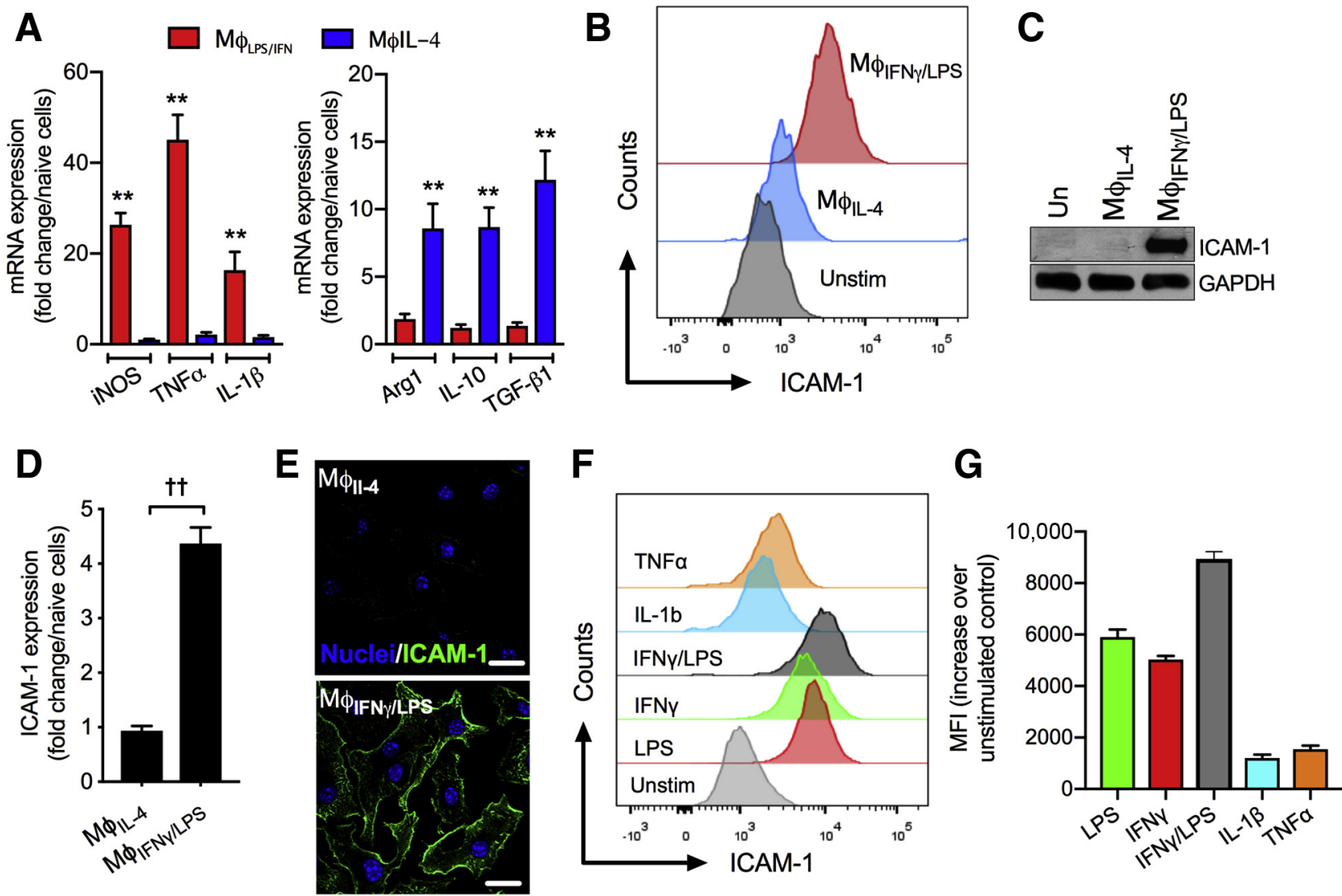

Figure 1 Intercellular adhesion molecule-1 (ICAM-1) expression is induced with macrophage inflammatory polarization. Murine bone marrow-derived macrophages were differentiated in culture and stimulated with IL-4 or interferon- $\gamma$ (IFN $\gamma$ )/lipopolysaccharide (LPS) to resemble tissue resident or inflammatory macrophages, respectively. A: Macrophage polarization into resident and inflammatory phenotype was confirmed by transcriptional analyses (quantitative RT-PCR) of the relevant genes. Data were normalized to unstimulated (naive) macrophages. B-E: Flow cytometry (B), Western blot (C), quantitative RT-PCR (D) and immunofluorescence staining (E) analyses show an induction of ICAM-1 expression in inflammatory (M $\left.\phi_{\text {IFN } \gamma / L P S}\right)$ but not in resident $\left(\mathrm{M}_{\phi_{\mathrm{IL}-4}}\right)$ or in undifferentiated and unstimulated macrophages. $\mathbf{F}$ and $\mathbf{G}$ : Differentiated macrophages were stimulated (for 24 hours) as indicated and ICAM-1 expression was assessed (representative flow diagram, $\mathbf{F}$ ) and quantified (G) using flow cytometry analyses. $n=3$ to 5 independent experiments. ${ }^{*} P<0.01$ versus naive macrophages; ${ }^{\dagger \dagger} P<0.01$. Scale bars $=20 \mu \mathrm{m}$. Arg1, arginase $1 ; \mathrm{GAPDH}$, glyceraldehyde-3-phosphate dehydrogenase; iNOS, inducible nitric oxide synthase; MFI, mean fluorescence intensity; mRNA, messenger RNA; TGF- $\beta 1$, transforming growth factor $\beta 1$; TNF $\alpha$, tumor necrosis factor $\alpha$; Unstim, unstimulated. 
propidium iodide and Annexin V staining. Apoptotic cells were added to plated BM-derived macrophages (2:1 ratio) and adherence was induced by low-speed centrifugation $(570 \times g, 3 \mathrm{~min})$. After incubation $\left(1\right.$ hour, $\left.37^{\circ} \mathrm{C}\right)$, loosely adhered cells were removed by gentle wash $(\times 3)$. The remaining cells were fixed (paraformaldehyde, 3.7\%) and engulfment was analyzed by image acquisition and cell count or flow cytometry. For cell counts, at least nine fields of view were acquired in duplicate per each independent experiment and macrophages that had engulfed ACs (acquisition of green fluorescence) were counted. All data are presented as a percentage of the total macrophages in the field of view.

For ICAM-1 inhibition experiments, macrophages were incubated with anti-ICAM-1 inhibitory or IgG control antibodies $(30 \mu \mathrm{g} / \mu \mathrm{L})$ or with Jasplakinolide $(1 \mu \mathrm{mol} / \mathrm{L}$ for 30 minutes) before the addition of apoptotic Jurkats or PMNs.

For assessment of efferocytosis by peritoneal macrophages, $3 \mathrm{~mL}$ of thioglycollate medium ( $3 \%$ in sterile water) was injected i.p. to elicit macrophage recruitment. On day 4 after thioglycollate administration, fluorescently tagged intestinal epithelial cells (IECs) isolated from E-
cadherin-CFP reporter mice (IEC-CFP) were injected into the peritoneal cavity for 2 hours. Peritoneal macrophages then were harvested by lavage as previously described ${ }^{38}$ and analyzed by flow cytometry for acquisition of CFP fluorescence.

For siRNA-mediated knockdown of ICAM-1 in THP-1 cells, siRNA transfection mix (ICAM-1 siRNA, $40 \mathrm{nmol} / \mathrm{L}$, OptiMEM transfection media and Lipofectamine 3000 in RPMI) was prepared and used per the manufacturer's instructions (Thermo Fisher Scientific). For all experimental conditions, assays were performed in duplicate.

\section{AC-Macrophage Adhesion}

To assess AC adhesion to macrophages, macrophages were pretreated with Jasplakinolide $(1 \mu \mathrm{mol} / \mathrm{L}$ for 30 minutes to prevent apoptotic cell engulfment). Subsequently, ACs were added to macrophages as detailed in efferocytosis experiments with/without the addition of anti-ICAM-1 inhibitory or IgG control antibodies. Data are shown as the percentage of macrophages with adherent $\mathrm{AC}$ relative to the total macrophage number in the field of view.
A

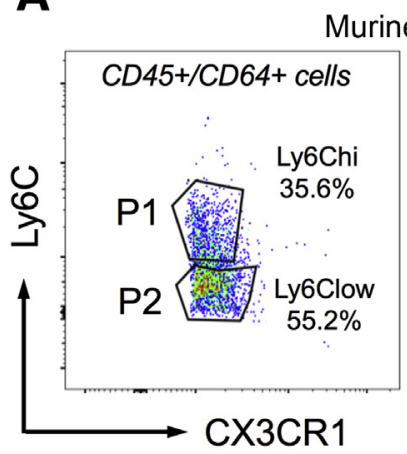

B

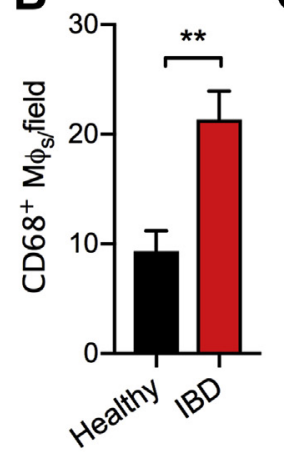

C

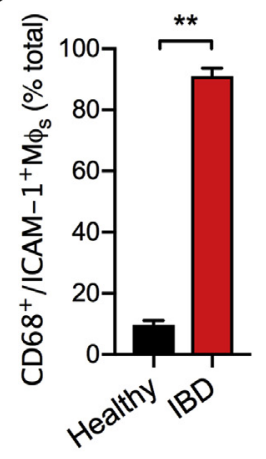

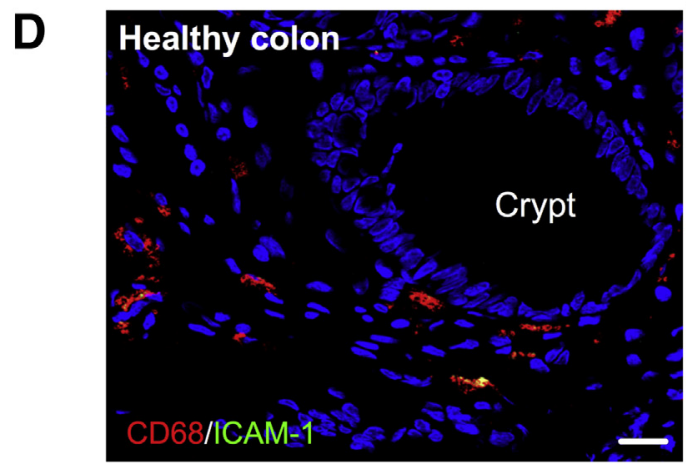

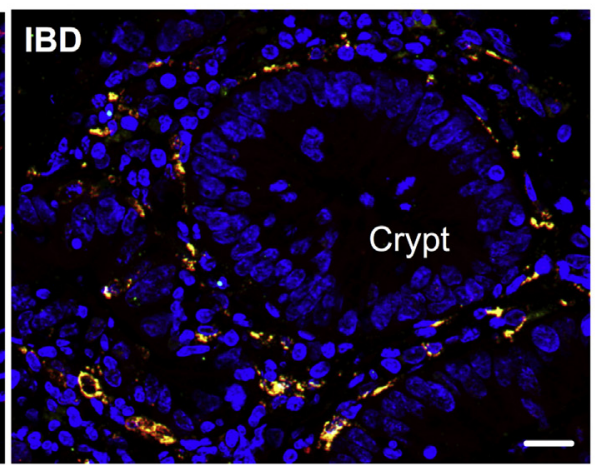

Figure 2 Inflammatory macrophages in murine and human colon tissue express intercellular adhesion molecule-1 (ICAM-1). A: Epithelial injury/colitis was induced by introduction of dextran sulfate sodium (DSS) $3 \%(\mathrm{w} / \mathrm{v})$ to drinking water for 7 days in CX3CR1-GFP macrophage reporter mice. Macrophages were isolated from the lamina propria of distal colons and ICAM-1 expression by CX3CR1/CD45/CD64-positive Ly6C $C^{\text {hi }}$ inflammatory (P1) versus Ly6 $C^{\text {low }}$ resident (P2) macrophages was analyzed by flow cytometry. B-D: Nonactive (noninflamed) control and active inflammatory bowel disease (IBD) colon tissue sections were stained by immunofluorescence for pan macrophage marker CD68 and ICAM-1. B: The number of CD68-positive macrophages per high-power field was quantified. C: The percentage of macrophages that were positive for both CD68 and ICAM-1 were quantified. D: Representative images show an increased number of CD86 and ICAM-1 expressing macrophages (yellow cells) in IBD tissue. $n=4$ independent experiments, with at least 10 fields quantified for human sections. ${ }^{* *} P<0.01$. Scale bars $=20 \mu \mathrm{m}$. 

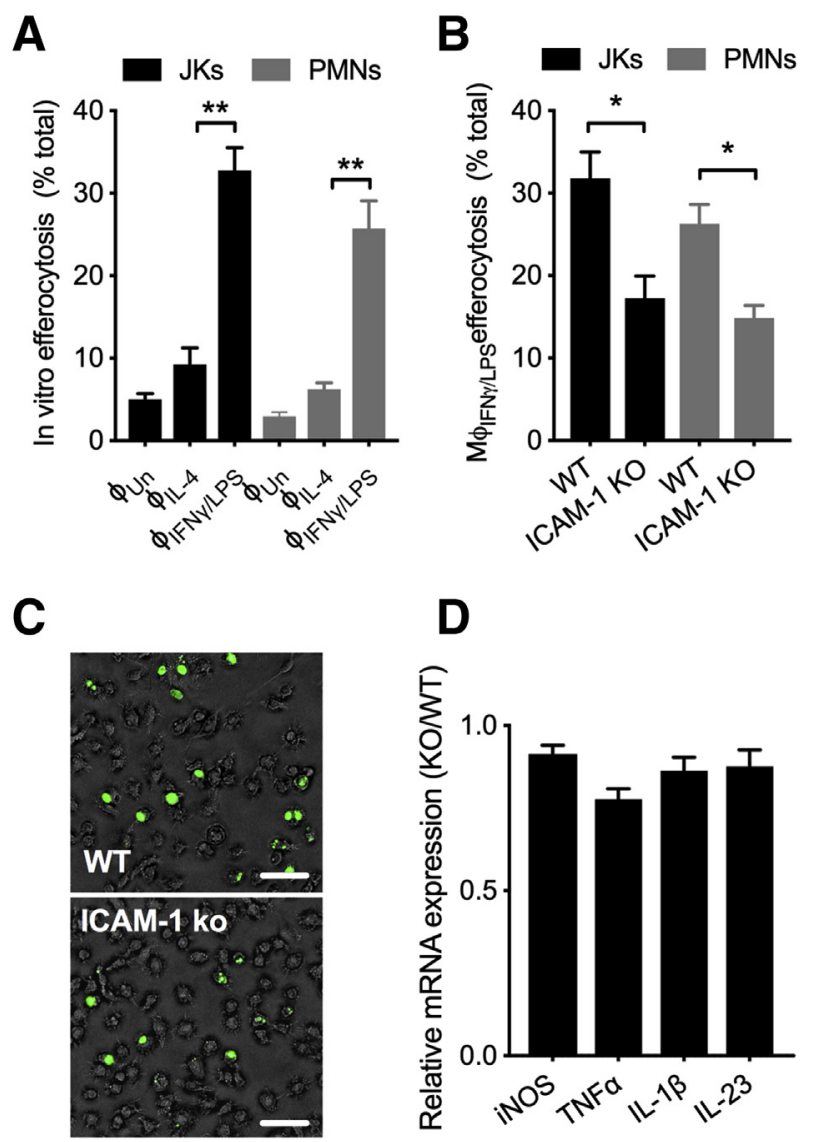

Figure 3 Intercellular adhesion molecule-1 (ICAM-1) contributes to efferocytosis by inflammatory macrophages ex vivo. Apoptotic cell (AC) engulfment assays were performed with bone marrow (BM)-derived macrophages undifferentiated or differentiated as indicated. A: Jurkats or murine BM-derived polymorphonuclear leukocytes (PMNs) were labeled fluorescently, irradiated to induce apoptosis, and incubated with undifferentiated macrophages or with $M \phi_{\text {IL- } 4}$ and $M \phi_{\text {IFN } \gamma / L P S}$. B: Efferocytotic ability was examined in $M \phi_{\text {IFN } \gamma / L P s}$ isolated from wild-type (WT) versus ICAM-1 knockout (KO) mice. C: Representative images depict impaired

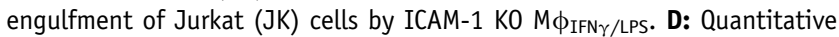
RT-PCR analyses were performed to determine inflammatory polarization of ICAM-1 KO M $\phi_{\text {IFN } \gamma / L P S}$. Data shown as KO relative to WT expression for each gene. $n=4$ independent experiments for each Jurkats and PMNs. ${ }^{*} P<0.05, P<0.01$. Scale bars $=20 \mu \mathrm{m}$. IFN $\gamma$, interferon- $\gamma$; iNOS, inducible nitric oxide synthase; LPS, lipopolysaccharide; mRNA, messenger RNA; TNF $\alpha$, tumor necrosis factor $\alpha$.

\section{Flow Cytometry}

Macrophages before or after efferocytosis assay were collected from tissue culture dishes using Cellstripper (Corning, Corning, NY) and prepared for flow cytometry as previously described. ${ }^{39}$ For isolated cells, doublet and smallcell aggregates were excluded based on forward scatter properties, and ICAM-1 expression at the cell surface was determined after incubation with fluorescently conjugated antibodies or relevant isotype controls for 40 minutes on ice. For efferocytosis in the peritoneum, $\mathrm{CD}^{+} 4^{+} / \mathrm{MHCII}^{+}$macrophages were analyzed. All cell samples were analyzed using BD FACSCanto II (Becton Dickinson, Franklin Lakes, NJ) and FlowJo 10 software (Becton Dickinson).

\section{Immunofluorescence Labeling}

To determine surface expression and localization of ICAM1, macrophages were seeded on coverslips, stimulated, and/ or co-incubated with ACs as needed. After treatment, cells were fixed with paraformaldehyde $3.7 \%$ in phosphatebuffered saline), blocked with 5\% bovine serum albumin in phosphate-buffered saline, and incubated with the relevant primary antibody $(\mathrm{Ab})\left(10 \mu \mathrm{g} / \mathrm{mL}\right.$, overnight at $\left.4^{\circ} \mathrm{C}\right)$ either directly conjugated or followed by an appropriate fluorescently labeled secondary antibody (1 hour at room temperature). For the mouse colitis/colon injury model, mice were treated with dextran sulfate sodium $(3 \% \mathrm{w} / \mathrm{v}$ in drinking water ${ }^{40-42}$ ). On day 7 mice were sacrificed, and colon tissue was extracted and frozen in optimal cutting temperature compound. Sections $(12 \mu \mathrm{m})$ were ethanolfixed and stained as described earlier in this paragraph for macrophage staining. Paraffin-embedded human healthy and inflammatory bowel disease (IBD) sections were subjected to antigen retrieval, methanol-fixed, permeabilized with 0.5 Triton X-100 (Sigma-Aldrich) solution as previously described, ${ }^{41}$ and stained for macrophage marker and ICAM-1 as described earlier in this paragraph. The use of human tissue was reviewed and approved by the Northwestern University Institutional Review Board. All images were captured using a Nikon A1R confocal microscope (Melville, NY) with $40 \times$ or $60 \times$ oil objectives.

\section{Gene Expression Analysis}

Total RNA from cultured human and mouse cells was extracted by TRIzol (Thermo Fisher Scientific, Applied Biosystems, Waltham, MA), subjected to DNase I (Promega, Madison, WI) treatment (3 U/mL reaction mixture), followed by an additional precipitation with TRIzol. An ND-1000 Spectrophotometer (NanoDrop Technologies, Wilmington, DE) was used to assess the quality and concentration of the RNA preparations. RT-PCR was performed with the Applied Biosciences complementary DNA Synthesis kit (Thermo Scientific). Gene expression analyses were performed on total complementary DNA using the SYBR Green Master Kit (Roche, South San Francisco, CA). The primers for gene- or microRNA-specific analysis by quantitative RT-PCR were custom designed and obtained from IDT (Newark, NJ) or Qiagen (QuantiTect Primer Assays kits; Germantown, MD). Relative expression analysis was performed using the delta-delta cycle treshold $(\mathrm{Ct})$ value $\left(2^{-\Delta \Delta \mathrm{Ct}}\right)$ method with $G A P D H$ serving as the reference gene. The PCR primers used in murine cells were as follows: inducible nitric oxide synthase (iNOS), forward: 5'-GTTCTCAGCCCAACAATACAAGA-3', reverse: 5'-GTGGACGGGTCGATGTCAC-3'; TNF $\alpha$, forward: 5'-CATCTTCTCAAAATTCGAGTGACAA- $3^{\prime}$, reverse: 5'-TGGGAGTAGACAAGGTACAACCC-3'; IL-1b, forward: 5'-CAACCAACAAGTGATATTCTCCATG-3', reverse: 5'-GATCCACACTCTCCAGCTGCA-3'; arginase 
1, forward: 5'-CAGAAGAATGGAAGAGTCAG-3', reverse: 5'-CAGATATGCAGGGAGTCACC-3'; IL-10, forward: $5^{\prime}$-TGAGGCGCTGTCGTCATCGATTTCTCCC3', reverse: 5'-ACCTGCTCCACTGCCTTGCT-3'; IL-23, forward: 5'-TGTGCCCCGATCCAGTGT-3', reverse: $5^{\prime}$ CGGATCCTTTGCAAGCAGAA- ${ }^{\prime}$; transforming growth factor $1 \mathrm{~b}$, forward: $5^{\prime}$-GCGGACTACTATGCTAAAGAGG$3^{\prime}$, reverse: $5^{\prime}$-GTAGAGTTCCACATGTTGCTCC- ${ }^{\prime}$; and ICAM-1, forward: 5'-GGTGAAGTCTGTCAAACAGGAGAT-3' ${ }^{\prime}$ reverse: 5'-GAGAGTGGTACAGTACTGTCA GGT-3'

\section{Western Blot}

BM-derived murine or THP-1 M $\phi$ s before or after differentiation and/or treatment were lysed in 1\% SDS buffer (with $100 \mathrm{mmol} / \mathrm{L}$ Tris $\mathrm{pH}$ 7.4) containing protease and phosphatase inhibitors (Sigma-Aldrich), boiled, and cleared by centrifugation. Equal amounts of protein from cell lysates (determined using a bovine serum albumin protein assay) were separated by SDS-PAGE and transferred onto nitrocellulose membranes. Membranes were blocked for 1 hour with 5\% nonfat milk in $0.05 \%$ Tween-20 Tris-buffered saline, and incubated with appropriate primary antibodies overnight at $4^{\circ} \mathrm{C}$, followed by secondary horseradish-peroxidase-conjugated antibodies.

\section{Statistics}

Statistical significance was assessed by an unpaired $t$-test or by one-way analysis of variance with a Newman-Keuls multiple comparison test using Prism software version 4.0 (GraphPad, San Diego, CA). Statistical significance was set at $P<0.05$.

\section{Results}

ICAM-1 Expression Is Induced with Macrophage Inflammatory Polarization

ICAM-1 is primarily known to mediate leukocyte adhesion to endothelial/epithelial layers; however, its expression also has been documented in tissue macrophages. ${ }^{21}$ Given the heterogeneity in tissue macrophage subsets ICAM-1 expression on resident versus inflammatory cells was examined. Murine BM-derived macrophages were differentiated in culture and stimulated with IL-4 $(20 \mathrm{ng} / \mathrm{mL})$ or IFN $\gamma /$ LPS (20/50 ng/mL, respectively) to resemble tissue resident and inflammatory macrophages, respectively. Consistent with the stimulation conditions, macrophage polarization toward the inflammatory $\left(\mathrm{M} \phi_{\mathrm{IFN} \gamma / \mathrm{LPS}}\right)$ and resident ( $\left.\mathrm{M} \phi_{\mathrm{IL}-4}\right)$ phenotypes was confirmed by expression analyses (quantitative RT-PCR) and up-regulation of iNOS, $\mathrm{TNF} \alpha$, and IL-1 $\beta$ in M $\phi_{\mathrm{IFN} \gamma / \mathrm{LPS}}$, and arginase 1 , IL-10, and transforming growth factor $1 \mathrm{~b}$ in $\mathrm{M} \phi_{\mathrm{IL}-4}$ (Figure 1A), as previously described. ${ }^{43}$ Further expression analyses by flow cytometry, Western blot, and quantitative RT-PCR showed that ICAM-1 levels were induced significantly in $\mathrm{M} \phi_{\mathrm{IFN} \gamma / \mathrm{LPS}}$, but were not detected in undifferentiated or $\mathrm{M} \phi_{\mathrm{IL}-4}$ (Figure 1, B-D). ICAM-1 up-regulation in M $\phi_{\mathrm{IFN} \gamma / \mathrm{LPS}}$ but not in $\mathrm{M} \phi_{\mathrm{IL}-4}$ was confirmed by immunofluorescence staining and confocal microscopy (Figure 1E). Stimulation of undifferentiated macrophages with IFN $\gamma$ or LPS alone was sufficient to induce ICAM-1 expression and was enhanced synergistically when both stimulants were used. Stimulation with IFN $\gamma$ and/or LPS was significantly more potent at inducing ICAM-1 up-regulation compared with other inflammatory cytokines, including $\mathrm{TNF} \alpha$ and IL-1 $\beta$, which are increased in injured tissues and can be produced by inflammatory macrophages (Figure 1, F and G).

\section{Inflammatory Macrophages in Murine and Human Colon Tissues Express ICAM-1}

CX3CR1-GFP macrophage reporter mice and a murine colitis/colon injury model (dextran sulfate sodium-induced) that simulates human colitis ${ }^{42}$ and elicits recruitment of $\mathrm{CD} 45^{+} \mathrm{CD} 64^{+} \mathrm{Ly} 6 \mathrm{C}^{\mathrm{hi}}$ inflammatory macrophages into the colon lamina propria ${ }^{44}$ were used to examine ICAM-1 expression in gut macrophages in vivo. Consistent with ex vivo observations in isolated macrophages, flow cytometry analyses of lamina propria macrophages (isolated by collagenase tissue digest after 7-day dextran sulfate sodium treatment ${ }^{44,45}$ ) showed a robust expression of ICAM-1 in $\mathrm{CX} 3 \mathrm{CR} 1{ }^{+} \mathrm{CD} 45^{+} \mathrm{CD} 64^{+}{ }^{+} \mathrm{Ly} 6 \mathrm{C}^{\mathrm{hi}}$ inflammatory, but not in $\mathrm{CX} 3 \mathrm{CR} 1{ }^{+} \mathrm{CD} 45^{+} \mathrm{CD} 64^{+} \mathrm{Ly} 6 \mathrm{C}^{\text {low }}$ resident, macrophages (Figure 2, A and B). The physiological relevance of these observations was substantiated further in human tissue sections from healthy and IBD patients. Immunofluorescence analyses showed that the number of $\mathrm{CD}^{+} 8^{+}$macrophages was increased significantly in active IBD colon tissue compared with nonactive (noninflamed) control tissue obtained from the same patients (Figure 2B). Importantly, although in noninflamed tissue less then $10 \%$ of all $\mathrm{CD} 68^{+}$ macrophages were found to express ICAM-1, in active IBD the majority (approximately 90\%) of all macrophages were positive for both CD68 and ICAM-1 (Figure 2, C and D).

\section{ICAM-1 Contributes to Efferocytosis by Inflammatory Macrophages ex Vivo}

One of the major functions of inflammatory macrophages is tissue debridement after injury. Given the observed induction in ICAM-1 expression by inflammatory macrophages it was asked whether ICAM-1 could contribute to efferocytosis (clearance of apoptotic/necrotic cells). Consistent with ICAM-1 expression patterns, it was found that inflammatory $\mathrm{M} \phi_{\mathrm{IFN} \gamma / \mathrm{LPS}}$, which up-regulate ICAM-1, were significantly more efficient at engulfing apoptotic (by irradiation) Jurkat $\mathrm{T}$ cells or murine primary BM-derived PMNs compared with undifferentiated BM-derived macrophages and $\mathrm{M} \phi_{\mathrm{IL}-4}$, both of which lack ICAM-1 (Figure 3A). To 


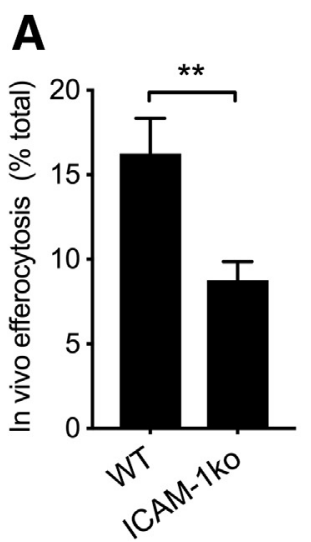

B

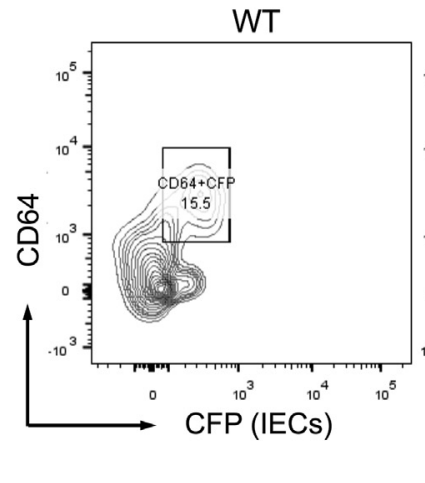

C

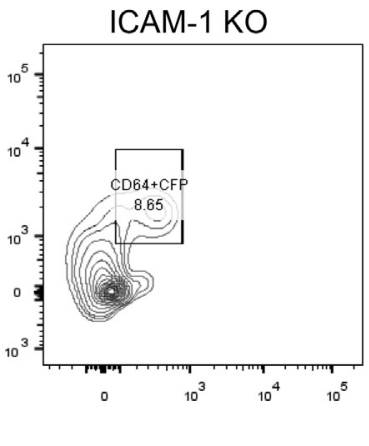

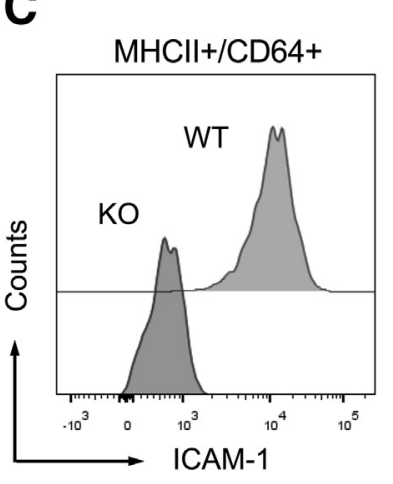

Figure 4 Intercellular adhesion molecule-1 (ICAM-1) facilitates apoptotic cell clearance in vivo. Apoptotic cell (AC) engulfment by peritoneal macrophages was examined. Mice were treated with thioglycollate to induce $M \phi$ recruitment to the peritoneal cavity. Mice were then injected with fluorescently tagged intestinal epithelial cells (IECS), which were isolated from E-cadherin-cyan fluorescence protein (CFP) mice and irradiated to induce apoptosis. A and B: Wildtype (WT) and ICAM-1 knockout (KO) Mфs were isolated by lavage, and engulfment of IEC-CFP (acquisition of CFP signal) by $\mathrm{MHCII}^{+} / \mathrm{CD}^{+} 4^{+}$peritoneal macrophages was quantified. C: ICAM- 1 expression was confirmed in WT but not in K0 macrophages. $N=3$ independent experiments with 2 to 3 mice for each experimental condition. ${ }^{* *} P<0.01$.

test the idea that ICAM-1 contributes to efferocytosis, engulfment assays were performed with $\mathrm{M} \phi_{\mathrm{IFN} \gamma / \mathrm{LPS}}$ isolated from ICAM-1 KO and the efferocytosis efficiency was compared with $\mathrm{M} \phi_{\mathrm{IFN} \gamma / \mathrm{LPS}}$ isolated from wild-type (WT) mice. Significant deficiency in efferocytosis by ICAM-1 KO macrophages was observed for both Jurkat cells and PMNs (Figure 3, B and C). Importantly, impaired efferocytosis by ICAM-1 KO macrophages was not owing to their inability to polarize toward an inflammatory phenotype because the expression of classic markers of inflammatory macrophages including iNOS, TNF $\alpha$, IL-1 $\beta$, and IL-23 was induced significantly in ICAM-1 KO macrophages and was not different from that in WT cells (Figure 3D).

\section{ICAM-1 Facilitates Apoptotic Cell Clearance in Vivo}

In injured tissue, macrophages would be tasked with the clearance of cells other than immune cells. Therefore, it was examined whether ICAM-1 contributes to the clearance of apoptotic/necrotic IECs by peritoneal $\mathrm{M} \phi \mathrm{s}$ in vivo. In these experiments, fluorescently tagged IECs were isolated from IEC-CFP reporter mice and irradiated to induce apoptosis. Apoptotic IEC-CFP mice subsequently were injected into the peritoneal cavity of WT and ICAM-1 KO mice after treatment with thioglycolate $(1 \mathrm{~mL}$ $3 \%$ sterile thioglycolate in water solution, i.p., 4 days), which induces $\mathrm{M} \phi$ recruitment into the peritoneal cavity. ${ }^{38,46}$ After a 2-hour incubation time, peritoneal $\mathrm{M} \phi \mathrm{s}$ were isolated by lavage and IEC-CFP engulfment, as indicated by the acquisition of CFP signal, which was quantified by flow cytometry. Because macrophages that are recruited into the peritoneal cavity by thioglycolate treatment have been shown to express higher levels of CD64 and MHCII and a lower level of F4/80 compared with naive peritoneal macrophages, ${ }^{38}$ the clearance of apoptotic/necrotic IECs was examined by $\mathrm{CD} 64^{+} / \mathrm{MHCII}^{+}$ macrophages. Consistent with ex vivo findings, efferocytosis by $\mathrm{CD}^{+} 4^{+} / \mathrm{MHCII}^{+}$macrophages was impaired
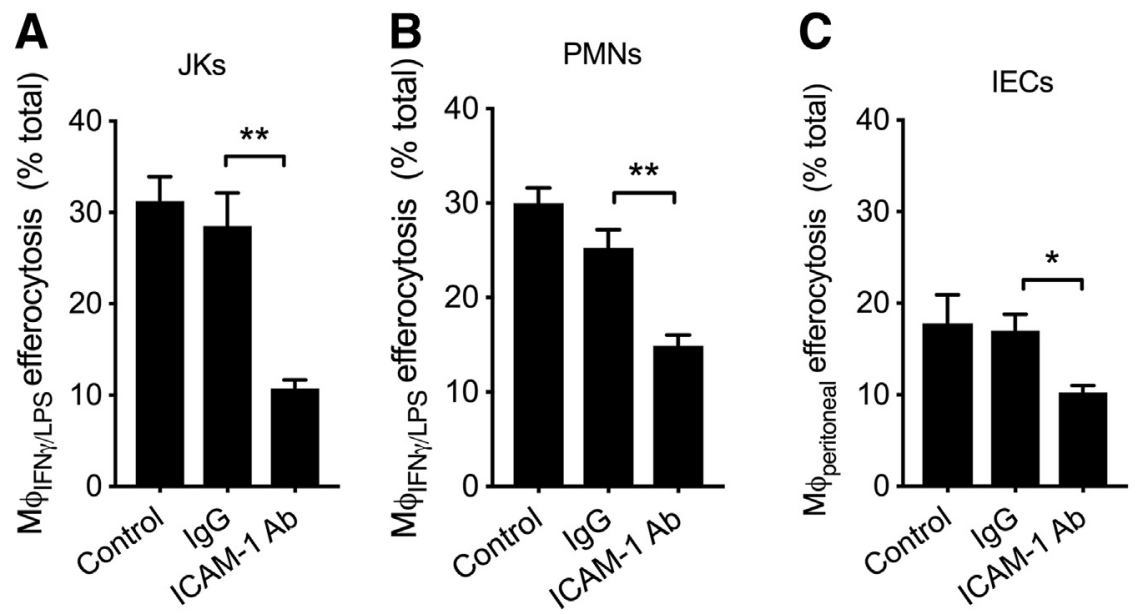

Figure 5 Intercellular adhesion molecule-1 (ICAM-1) promotes efferocytosis by mediating macrophage-apoptotic cell $(A C)$ binding. Engulfment of apoptotic (A) Jurkat (JK) cells and (B) polymorphonuclear leukocytes (PMNs) by wild-type bone marrow-derived $M \phi_{\text {IFN } / \text { LPS }}$ or $(\mathbf{C})$ intestinal epithelial cells (IECs) by thioglycollate-recruited peritoneal $\mathrm{MHCII}^{+} / \mathrm{CD} 4^{+}$macrophages, with or without the addition of function blocking ICAM-1 or control IgG antibodies (Abs) was examined. Inhibition of ICAM- 1 adhesive interactions impairs efferocytosis for all conditions. $n=3$ independent experiments for each condition. ${ }^{*} P<0.05$, ${ }^{* * P}<0.01$. IFN $\gamma$, interferon- $\gamma ;$ LPS, lipopolysaccharide. 


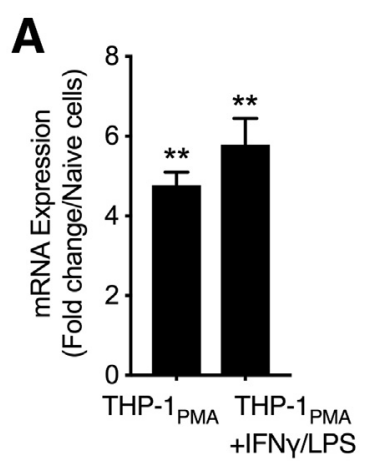

D

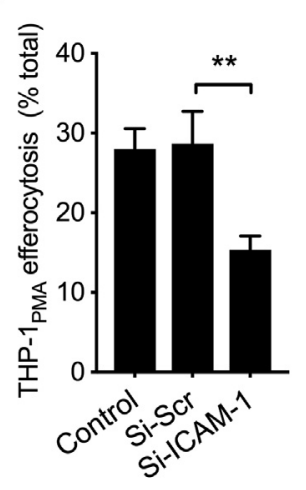

B
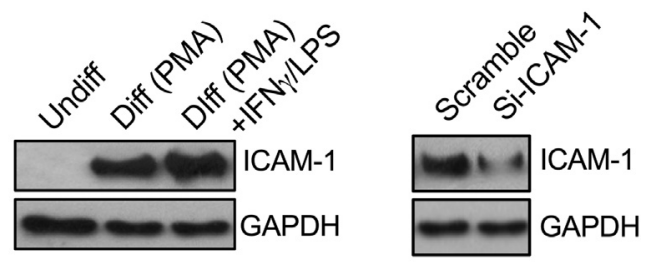

E

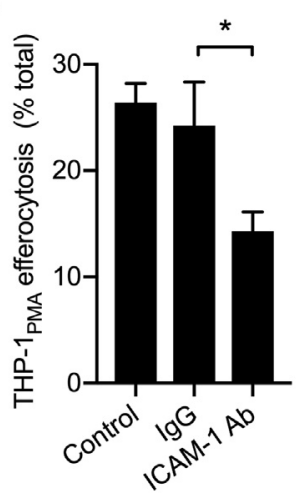

$\mathbf{F}$

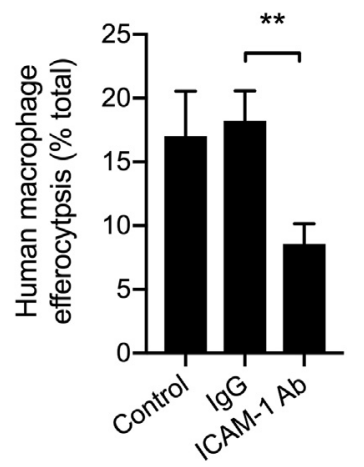

Figure 6 Intercellular adhesion molecule-1 (ICAM-1) facilitates efferocytosis in human THP-1 macrophages. A-E: THP-1 macrophages were differentiated toward inflammatory phenotype by PMA treatment (THP-1 PMA $_{\text {) with and }}$ without further stimulation with interferon- $\gamma(\operatorname{IFN} \gamma) /$ lipopolysaccharide (LPS). A and B: Messenger RNA (mRNA) transcript (A) and protein analyses (B) shows a significant induction in ICAM-1 expression. C: Knockdown of ICAM-1 protein was confirmed by Western blot. D: Apoptotic cell (AC) (Jurkats) engulfment assays were performed with/ without siRNA-mediated down-regulation of ICAM-1 expression, showing impaired engulfment in the absence of functional ICAM-1. E: Engulfment assays were performed similarly with/without the addition of function blocking ICAM-1 or control IgG antibodies (Abs). F: AC engulfment assays were performed using primary human monocyte-derived macrophages activated with IFN $\gamma /$ LPS treatment, with/without the addition of function blocking ICAM-1 or control IgG Abs. Inhibition of ICAM-1 adhesive interactions impaired THP-1 and primary macrophage efferocytosis. $n=4$ independent experiments. ${ }^{*} P<0.05$, ${ }^{* *} P<0.01$. Diff, differentiated; GAPDH, glyceraldehyde3-phosphate dehydrogenase; Si-ICAM-1, small interferingICAM-1; Si-Scr, small-interfering scrample; Undiff, undifferentiated.

significantly in ICAM-1 KO compared with WT mice (Figure $4, \mathrm{~A}$ and $\mathrm{B}$ ). $\mathrm{CD}^{+} 4^{+} \mathrm{MHCII}^{+}$peritoneal macrophages in WT mice were confirmed to express high levels of ICAM-1 as opposed to ICAM-1 KO macrophages (Figure 4C). A similar deficiency in IEC-CFP engulfment was confirmed in vitro by ICAM-1 KO M $\phi_{\mathrm{IFN} \gamma / \mathrm{LPS}}$ (not shown).

\section{ICAM-1 Promotes Efferocytosis by Mediating Macrophage-AC Binding}

ICAM-1 functions as an adhesion receptor on endothelial and epithelial cells. Thus, it was examined whether ICAM-1 contributes to efferocytosis by facilitating macrophage- $\mathrm{AC}$ binding interactions. To this end, in vitro and in vivo engulfment assays were performed with WT macrophages and the addition of a function inhibitory anti-ICAM-1 Ab. Engulfment of apoptotic Jurkat cells and PMNs by WT M $\phi_{\mathrm{IFN} \gamma / \mathrm{LPS}}$ was reduced significantly with the Ab-mediated inhibition of ICAM- $1 \mathrm{Ab}(30 \mu \mathrm{g} / \mathrm{mL}, 30$ minutes before the addition of ACs) (Figure 5, A and B). Similarly, co-administration of anti-ICAM-1 inhibitory Abs together with apoptotic IECCFP to the inflamed peritoneum resulted in a significant reduction of IEC clearance by $\mathrm{MHCII}^{+} / \mathrm{CD}^{+} 4^{+}$peritoneal macrophages (Figure 5C). These data indicate that ICAM-1 promotes macrophage efferocytosis by mediating cell-to-cell adhesion.
The contribution of ICAM-1 to macrophage efferocytosis was confirmed further in the human THP-1 macrophage cell line. Transcript and protein analyses showed a significant induction in ICAM-1 expression in THP-1 cells that were differentiated toward an inflammatory phenotype by PMA treatment (THP-1 $1_{\mathrm{PMA}}$ ), with and without subsequent stimulation with IFN $\gamma /$ LPS (Figure 6, A and B). Consistent with murine macrophages, siRNA-mediated down-regulation of ICAM-1 expression in human THP- $1_{\text {PMA }}$ macrophages [ $>85 \%$ knockdown, confirmed at the mRNA (not shown) and protein levels] (Figure 6C) resulted in significantly decreased AC engulfment (Figure 6D). Consistent with the idea of ICAM-1 contribution to macrophage efferocytosis by mediating adhesive interactions, engulfment of ACs by THP- $1_{\text {PMA }}$ was reduced significantly with Ab-mediated inhibition of ICAM-1 (Figure 6E). Finally, impairment in efferocytosis with Ab-mediated inhibition of ICAM-1 was confirmed in primary human monocyte-derived inflammatory macrophages (Figure 6F).

\section{ICAM-1 Redistributes to the Engulfment Site to Mediate Macrophage-AC Attachment}

Immunofluorescence staining and confocal microscopy imaging experiments were performed to determine ICAM-1 localization on the macrophage surface during efferocytosis. Imaging experiments showed that during $\mathrm{M} \phi_{\mathrm{IFN} \gamma / \mathrm{LPS}}$ efferocytosis ICAM-1 was actively redistributed to cluster 


\section{A ICAM-1}

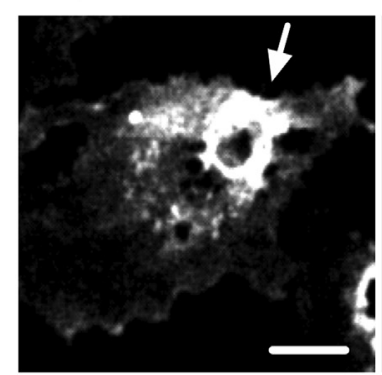

B

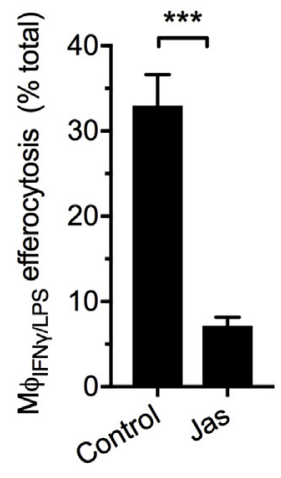

JK

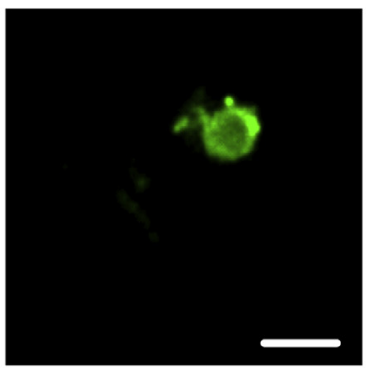

C

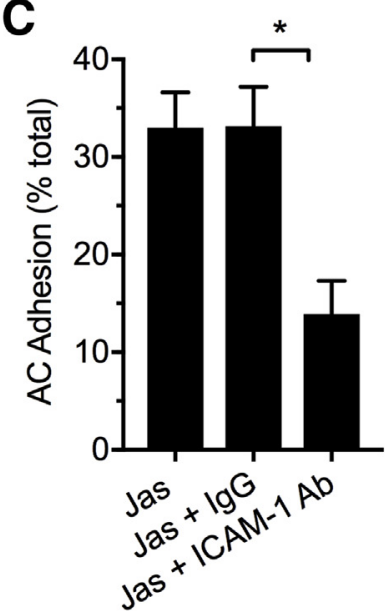

Merge

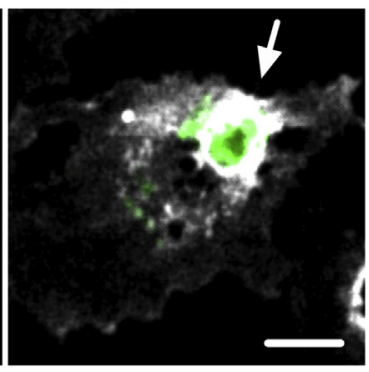

D
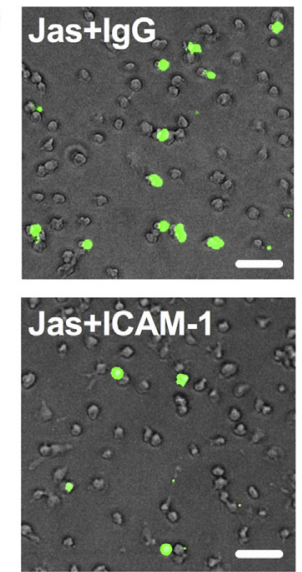

Figure 7 Intercellular adhesion molecule-1 (ICAM-1) redistributes to the engulfment site to mediate apoptotic cell (AC) attachment. AC [Jurkat $(\mathrm{JK})$ ] engulfment assays by wild-type $M \phi_{\mathrm{IFN} \gamma / \mathrm{LPS}}$ were performed. A: In the process of engulfment, $M \phi_{\text {IFN } \gamma / L P S}$ were fixed and fluorescently stained for surface ICAM-1 (no permeabilization). Confocal microscopy was used to determine ICAM-1 localization with respect to engulfed ACs. Representative images show ICAM-1 clustering at the site of engulfed AC (white arrows). B: $M \phi_{\text {IFN } \gamma / L P S}$ were treated with Jasplakinolide (Jas) to block the ability of macrophages to engulf ACs. C: $A C$ attachment to $\phi_{\text {IFN } / \text { LPS }}$ was quantified with/ without the addition of function blocking ICAM-1 or control IgG antibodies (Abs). D: Representative images show a significant reduction in $A C$ attachment to $\phi_{\text {IFN } \gamma / \text { LPS }}$ with ICAM- 1 inhibition. $n=3$ independent experiments for each condition. ${ }^{*} P<0.05,{ }^{* * *} P<0.001$. Scale bars $=20 \mu \mathrm{m}$ (A and D). IFN $\gamma$, interferon- $\gamma$; LPS, lipopolysaccharide. around ACs that were being engulfed (Figure 7A), supporting the idea of ICAM-1-mediated macrophage-AC attachment. To test whether ICAM-1 indeed promotes efferocytosis by facilitating $\mathrm{M} \phi-\mathrm{AC}$ attachment, Jasplakinolide ( $1 \mu \mathrm{mol} / \mathrm{L}$, an actin stabilizing agent) was used to block the ability of macrophages to engulf ACs. Because rapid reorganization of the actin cytoskeleton is essential for the phagocytic cup formation and internalization of $\mathrm{ACs},{ }^{47}$ as expected, Jasplakinolide treatment prevented $\mathrm{AC}$ engulfment (Figure 7B). Importantly, in this setup, in which macrophages cannot engulf ACs, Ab-mediated inhibition of ICAM-1 resulted in significantly decreased AC adhesion to macrophages (Figure 7, C and D). In these experiments, Abs were added together with Jasplakinolide $(30 \mu \mathrm{g} / \mathrm{mL}, 30$ minutes) before the addition of ACs. These data confirm the role of ICAM-1 in mediating macrophage-AC binding during efferocytosis.

\section{Discussion}

ICAM-1 is up-regulated in inflamed tissue and serves to mediate adhesion of immune cells to endothelial cells, epithelial cells, and, in some cases, other immune cells. As such, it is a critical receptor that facilitates the initiation and progression of inflammatory responses. In the current work, we identified yet another uncharacterized function of ICAM-1 that can contribute to the resolution of inflammation. It was found that ICAM-1 expression is induced in inflammatory macrophages and that ICAM-1 plays an important role in macrophage efferocytosis, a process that is critical for resolution of inflammation and wound healing. Our data specifically implicate ICAM-1 in receptor-mediated binding and engulfment of apoptotic/ necrotic cells, which are key steps in the efferocytotic cascade.

Studies were performed in murine BM-derived and peritoneal macrophages as well as macrophages derived from a human monocytic cell line and primary blood monocytes. Macrophage stimulation with IFN $\gamma /$ LPS induced ICAM-1 expression and was accompanied with up-regulation of other known markers of inflammatory macrophage polarization, including iNOS, TNF $\alpha$, IL-1 $\beta$, and IL-23. Although these markers are commonly used to define inflammatory macrophages, the emerging macrophage plasticity in various organs and inflammatory conditions led to the identification of many other markers both unique to this subset as well as markers with overlapping expression in other macrophage subsets. ${ }^{48,49}$ A degree of specificity was observed in the ICAM-1 response. The IFN $\gamma$ or LPS stimulation alone was sufficient to induce ICAM-1 expression, and ICAM-1 levels were augmented synergistically by combined treatment. Interestingly, although macrophage stimulation with other inflammatory cytokines, such as TNF $\alpha$ or IL- $1 \beta$, increased ICAM-1 
expression, they had a relatively small effect compared with IFN $\gamma$ or LPS stimulation. Given the role of IFN $\gamma /$ LPS in driving inflammatory polarization of macrophages, this suggests that molecular reprogramming rather than exposure to the inflammatory milieu primarily drives ICAM-1 expression. The physiological relevance of these observations was confirmed further in a murine model of colitis and in human IBD, in which similar to observations in isolated cells, inflammatory macrophages that are recruited to the lamina propria in disease were found to express high ICAM-1 levels.

Although how ICAM-1 expression is regulated in macrophages still is not well-defined, increased iNOS and reactive oxygen species have been suggested to mechanistically promote ICAM-1 up-regulation. ${ }^{50}$ In contrast, transforming growth factor $\beta$, which gradually was up-regulated after peritoneal macrophage infection with Mycobacterium avium complexes, was shown to promote ICAM-1 downregulation. ${ }^{51}$ These data support the idea that ICAM-1 induction is linked to inflammatory macrophage polarization. Interestingly, given the macrophage phenotypic and functional heterogeneity in vivo, whether the induction of ICAM-1 expression is a common feature of inflammatory macrophages or a characteristic of a specific cellular subtype with a defined function is another important question to be explored in the future using emerging technologies, such as single-cell RNA sequencing.

In endothelial cells, ICAM-1 expression is induced by nuclear factor $\kappa \mathrm{B}$ in response to TNF $\alpha$ or IL- $1 \beta$ stimulation, ${ }^{52}$ but in intestinal epithelial cells ICAM-1 expression is induced by IFN $\gamma$ treatment rather than by $\mathrm{TNF} \alpha$ or LPS treatment. ${ }^{5}$ This indicates that the regulation of ICAM-1 expression is cell-type-specific. Given the restricted expression patterns of ICAM-1 that we have uncovered, this information could be used in the future to delineate macrophages of an inflammatory nature.

Importantly, ICAM-1 up-regulation was found to impact macrophage efferocytotic ability. Ablation of ICAM-1 in murine or human macrophages significantly impaired their ability to engulf apoptotic/necrotic cells. This was true for macrophage uptake of both immune cells (T lymphocytes and PMNs) and intestinal epithelial cells. In the setting of bacterial infection and tissue injury, clearance of immune cells terminates the inflammatory response to initiate injury resolution, while removal of dead epithelial cells facilitates wound resealing and minimizes tissue fibrosis. As such, ICAM-1 up-regulation in macrophages may play an important role in the initiation of inflammatory resolution and wound healing.

ICAM-1 on the macrophage surface was found to be actively redistributed to the site of the engulfed AC and to facilitate AC attachment to macrophages. Rapid ICAM-1 redistribution in response to an inflammatory stimulus has been observed previously in endothelial cells, where it localizes to lipid rafts. ${ }^{53}$ Endothelial ICAM-1 has been shown to redistribute and become enriched at the sites of leukocyte adhesion, forming ring- like structures, essential for leukocyte transendothelial migration. ${ }^{54,55}$ ICAM-1 also has been shown to redistribute to the endothelial cell tricellular junction in inflamed vasculature to facilitate neutrophil recruitment. ${ }^{56}$ As such, ICAM-1 motility at the cell surface membrane is essential for its regulatory function in guiding leukocyte transendothelial migration.

ICAM-1 has been best studied in endothelial cells, where it mediates the attachment of immune cells, including PMNs, monocytes, and lymphocytes to endothelial cells. ICAM-1 is known to bind to $\beta 2$-integrins, CD11b (Mac1), and CD11a (LFA1), all of which are expressed at varying levels on most immune cells. ${ }^{1,57}$ Upon immune cell activation, both integrins undergo affinity-induced conformation change to subsequently bind ICAM-1. As such, it is highly likely that the ICAM-1 on macrophages similarly binds $\beta 2$-integrins on immune cells to facilitate the formation of efferocytotic synapses between macrophages and apoptotic immune cells. However, this should be confirmed in future work. Interestingly, we found that inhibition of ICAM-1-mediated adhesive interactions similarly impaired epithelial cell uptake. Because $\beta 2$-integrin expression is restricted to immune cells, these data suggest that ICAM-1 may bind an as yet unknown epithelial receptor. This is a novel finding that we plan to explore in future work.

In summary, our work has identified a new physiological role of ICAM-1 in inflammatory macrophages. ICAM-1 has been found to actively redistribute to the AC engulfment site to promote macrophage-AC attachment. As such, by enhancing macrophage efferocytosis, ICAM-1 may promote beneficial macrophage functions in inflamed/injured tissue, contributing to resolution of inflammation. Furthermore, because ICAM-1 expression is restricted to inflammatory macrophages, our data suggest that it can be used as an additional marker to phenotypically categorize macrophage polarization during inflammation.

\section{Author Contributions}

H.L.W., T.M.B., A.F., E.B.T., and R.S. designed the study; H.L.W., T.M.B., A.F., P.D., A.B., and J.J.L. performed experiments and analyzed data; H.L.W., T.M.B., and R.S. wrote the manuscript.

\section{References}

1. Diamond MS, Staunton DE, de Fougerolles AR, Stacker SA, GarciaAguilar J, Hibbs ML, Springer TA: ICAM-1 (CD54): a counterreceptor for Mac-1 (CD11b/CD18). J Cell Biol 1990, 111: 3129-3139

2. Kaiserlian D, Rigal D, Abello J, Revillard JP: Expression, function and regulation of the intercellular adhesion molecule-1 (ICAM-1) on human intestinal epithelial cell lines. Eur J Immunol 1991, 21: 2415-2421

3. Sumagin R, Sarelius IH: TNF-alpha activation of arterioles and venules alters distribution and levels of ICAM-1 and affects leukocyte- 
endothelial cell interactions. Am J Physiol Heart Circ Physiol 2006, 291:H2116-H2125

4. Xia YF, Liu LP, Zhong CP, Geng JG: NF-kappaB activation for constitutive expression of VCAM-1 and ICAM-1 on B lymphocytes and plasma cells. Biochem Biophys Res Commun 2001, 289:851-856

5. Sumagin R, Robin AZ, Nusrat A, Parkos CA: Transmigrated neutrophils in the intestinal lumen engage ICAM-1 to regulate the epithelial barrier and neutrophil recruitment. Mucosal Immunol 2014, 7:905-915

6. Byeseda SE, Burns AR, Dieffenbaugher S, Rumbaut RE, Smith CW, Li Z: ICAM-1 is necessary for epithelial recruitment of gammadelta T cells and efficient corneal wound healing. Am J Pathol 2009, 175: 571-579

7. Etienne-Manneville S, Manneville JB, Adamson P, Wilbourn B, Greenwood J, Couraud PO: ICAM-1-coupled cytoskeletal rearrangements and transendothelial lymphocyte migration involve intracellular calcium signaling in brain endothelial cell lines. J Immunol 2000, 165:3375-3383

8. Sumagin R, Sarelius IH: A role for ICAM-1 in maintenance of leukocyte-endothelial cell rolling interactions in inflamed arterioles. Am J Physiol Heart Circ Physiol 2007, 293:H2786-H2798

9. Yang L, Froio RM, Sciuto TE, Dvorak AM, Alon R, Luscinskas FW: ICAM-1 regulates neutrophil adhesion and transcellular migration of TNF-alpha-activated vascular endothelium under flow. Blood 2005, 106:584-592

10. Sumagin R, Lomakina E, Sarelius IH: Leukocyte-endothelial cell interactions are linked to vascular permeability via ICAM-1-mediated signaling. Am J Physiol Heart Circ Physiol 2008, 295:H969-H977

11. Allingham MJ, van Buul JD, Burridge K: ICAM-1-mediated, Srcand Pyk2-dependent vascular endothelial cadherin tyrosine phosphorylation is required for leukocyte transendothelial migration. J Immunol 2007, 179:4053-4064

12. Gay AN, Mushin OP, Lazar DA, Naik-Mathuria BJ, Yu L, Gobin A, Smith CW, Olutoye OO: Wound healing characteristics of ICAM-1 null mice devoid of all isoforms of ICAM-1. J Surg Res 2011, 171:e1-e7

13. Sumagin R, Brazil JC, Nava P, Nishio H, Alam A, Luissint AC, Weber DA, Neish AS, Nusrat A, Parkos CA: Neutrophil interactions with epithelial-expressed ICAM-1 enhances intestinal mucosal wound healing. Mucosal Immunol 2016, 9:1151-1162

14. Stewart MP, Cabanas C, Hogg N: T cell adhesion to intercellular adhesion molecule-1 (ICAM-1) is controlled by cell spreading and the activation of integrin LFA-1. J Immunol 1996, 156: $1810-1817$

15. Chirathaworn C, Kohlmeier JE, Tibbetts SA, Rumsey LM, Chan MA Benedict SH: Stimulation through intercellular adhesion molecule-1 provides a second signal for $\mathrm{T}$ cell activation. J Immunol 2002, 168:5530-5537

16. Cox MA, Barnum SR, Bullard DC, Zajac AJ: ICAM-1-dependent tuning of memory CD8 T-cell responses following acute infection. Proc Natl Acad Sci U S A 2013, 110:1416-1421

17. Woodfin A, Beyrau M, Voisin MB, Ma B, Whiteford JR, Hordijk PL, Hogg N, Nourshargh S: ICAM-1-expressing neutrophils exhibit enhanced effector functions in murine models of endotoxemia. Blood 2016, 127:898-907

18. Lohri C, Schaltegger CS, van den Broek M, Wenger RH, Ruegg C, Fink D, Fehr MK, Knuth A, Zweifel M: Neutrophil expression of ICAM1, CXCR1, and VEGFR1 in patients with breast cancer before and after adjuvant chemotherapy. Anticancer Res 2014, 34: 4693-4699

19. Bernatchez SF, Atkinson MR, Parks PJ: Expression of intercellular adhesion molecule-1 on macrophages in vitro as a marker of activation. Biomaterials 1997, 18:1371-1378

20. Yang M, Liu J, Piao C, Shao J, Du J: ICAM-1 suppresses tumor metastasis by inhibiting macrophage M2 polarization through blockade of efferocytosis. Cell Death Dis 2015, 6:e1780

21. Gu W, Yao L, Li L, Zhang J, Place AT, Minshall RD, Liu G: ICAM-1 regulates macrophage polarization by suppressing MCP-1 expression via miR-124 upregulation. Oncotarget 2017, 8: 111882-111901

22. Korns D, Frasch SC, Fernandez-Boyanapalli R, Henson PM, Bratton DL: Modulation of macrophage efferocytosis in inflammation. Front Immunol 2011, 2:57

23. Lemke G, Burstyn-Cohen T: TAM receptors and the clearance of apoptotic cells. Ann N Y Acad Sci 2010, 1209:23-29

24. Yurdagul A Jr, Doran AC, Cai B, Fredman G, Tabas IA: Mechanisms and consequences of defective efferocytosis in atherosclerosis. Front Cardiovasc Med 2017, 4:86

25. Wan E, Yeap XY, Dehn S, Terry R, Novak M, Zhang S, Iwata S, Han X, Homma S, Drosatos K, Lomasney J, Engman DM, Miller SD, Vaughan DE, Morrow JP, Kishore R, Thorp EB: Enhanced efferocytosis of apoptotic cardiomyocytes through myeloid-epithelialreproductive tyrosine kinase links acute inflammation resolution to cardiac repair after infarction. Circ Res 2013, 113:1004-1012

26. Chen J, Carey K, Godowski PJ: Identification of Gas6 as a ligand for Mer, a neural cell adhesion molecule related receptor tyrosine kinase implicated in cellular transformation. Oncogene 1997, 14:2033-2039

27. Soki FN, Koh AJ, Jones JD, Kim YW, Dai J, Keller ET, Pienta KJ, Atabai K, Roca H, McCauley LK: Polarization of prostate cancerassociated macrophages is induced by milk fat globule-EGF factor 8 (MFG-E8)-mediated efferocytosis. J Biol Chem 2014, 289: $24560-24572$

28. Zhang S, Weinberg S, DeBerge M, Gainullina A, Schipma M, Kinchen JM, Ben-Sahra I, Gius DR, Yvan-Charvet L, Chandel NS, Schumacker PT, Thorp EB: Efferocytosis fuels requirements of fatty acid oxidation and the electron transport chain to polarize macrophages for tissue repair. Cell Metab 2019, 29:443-456 e5

29. Fadok VA, Bratton DL, Konowal A, Freed PW, Westcott JY, Henson PM: Macrophages that have ingested apoptotic cells in vitro inhibit proinflammatory cytokine production through autocrine/paracrine mechanisms involving TGF-beta, PGE2, and PAF. J Clin Invest 1998, 101:890-898

30. Xiao YQ, Freire-de-Lima CG, Schiemann WP, Bratton DL, Vandivier RW, Henson PM: Transcriptional and translational regulation of TGF-beta production in response to apoptotic cells. J Immunol 2008, 181:3575-3585

31. Khanna S, Biswas S, Shang Y, Collard E, Azad A, Kauh C, Bhasker V, Gordillo GM, Sen CK, Roy S: Macrophage dysfunction impairs resolution of inflammation in the wounds of diabetic mice. PLoS One 2010, 5:e9539

32. Dreskin SC, Thomas GW, Dale SN, Heasley LE: Isoforms of Jun kinase are differentially expressed and activated in human monocyte/macrophage (THP-1) cells. J Immunol 2001, 166:5646-5653

33. Morioka S, Perry JSA, Raymond MH, Medina CB, Zhu Y, Zhao L, Serbulea V, Onengut-Gumuscu S, Leitinger N, Kucenas S, Rathmell JC, Makowski L, Ravichandran KS: Efferocytosis induces a novel SLC program to promote glucose uptake and lactate release. Nature 2018, 563:714-718

34. Amend SR, Valkenburg KC, Pienta KJ: Murine hind limb long bone dissection and bone marrow isolation. J Vis Exp 2016, 110:53936

35. Dalli J, Serhan CN: Specific lipid mediator signatures of human phagocytes: microparticles stimulate macrophage efferocytosis and pro-resolving mediators. Blood 2012, 120:e60-e72

36. Slater TW, Finkielsztein A, Mascarenhas LA, Mehl LC, ButinIsraeli V, Sumagin R: Neutrophil microparticles deliver active myeloperoxidase to injured mucosa to inhibit epithelial wound healing. J Immunol 2017, 198:2886-2897

37. Finkielsztein A, Mascarenhas L, Butin-Israeli V, Sumagin R: Isolation and characterization of neutrophil-derived microparticles for functional studies. J Vis Exp 2018, 133:56949

38. Pavlou S, Wang L, Xu H, Chen M: Higher phagocytic activity of thioglycollate-elicited peritoneal macrophages is related to metabolic status of the cells. J Inflamm (Lond) 2017, 14:4

39. Weber DA, Sumagin R, McCall IC, Leoni G, Neumann PA, Andargachew R, Brazil JC, Medina-Contreras O, Denning TL, 
Nusrat A, Parkos CA: Neutrophil-derived JAML inhibits repair of intestinal epithelial injury during acute inflammation. Mucosal Immunol 2014, 7:1221-1232

40. Kim JJ, Shajib MS, Manocha MM, Khan WI: Investigating intestinal inflammation in DSS-induced model of IBD. J Vis Exp 2012, 60:3678

41. Butin-Israeli V, Bui TM, Wiesolek HL, Mascarenhas L, Lee JJ, Mehl LC, Knutson KR, Adam SA, Goldman RD, Beyder A, Wiesmuller L, Hanauer SB, Sumagin R: Neutrophil-induced genomic instability impedes resolution of inflammation and wound healing. J Clin Invest 2019, 129:712-726

42. Chassaing B, Aitken JD, Malleshappa M, Vijay-Kumar M: Dextran sulfate sodium (DSS)-induced colitis in mice. Curr Protoc Immunol 2014, 104:15.25.1-15.25.14

43. Martinez FO, Gordon S: The M1 and M2 paradigm of macrophage activation: time for reassessment. F1000Prime Rep 2014, 6:13

44. Quiros M, Nishio H, Neumann PA, Siuda D, Brazil JC, Azcutia V, Hilgarth R, O'Leary MN, Garcia-Hernandez V, Leoni G, Feng M, Bernal G, Williams H, Dedhia PH, Gerner-Smidt C, Spence J, Parkos CA, Denning TL, Nusrat A: Macrophage-derived IL-10 mediates mucosal repair by epithelial WISP-1 signaling. J Clin Invest 2017, 127:3510-3520

45. Medina-Contreras O, Geem D, Laur O, Williams IR, Lira SA, Nusrat A, Parkos CA, Denning TL: CX3CR1 regulates intestinal macrophage homeostasis, bacterial translocation, and colitogenic Th17 responses in mice. J Clin Invest 2011, 121:4787-4795

46. Zhang X, Goncalves R, Mosser DM: The isolation and characterization of murine macrophages. Curr Protoc Immunol 2008, 14:14.1

47. Rougerie P, Miskolci V, Cox D: Generation of membrane structures during phagocytosis and chemotaxis of macrophages: role and regulation of the actin cytoskeleton. Immunol Rev 2013, 256:222-239

48. Gensel JC, Kopper TJ, Zhang B, Orr MB, Bailey WM: Predictive screening of M1 and M2 macrophages reveals the immunomodulatory effectiveness of post spinal cord injury azithromycin treatment. Sci Rep 2017, 7:40144
49. Zhu Y, Zhang L, Lu Q, Gao Y, Cai Y, Sui A, Su T, Shen X, Xie B: Identification of different macrophage subpopulations with distinct activities in a mouse model of oxygen-induced retinopathy. Int J Mol Med 2017, 40:281-292

50. Hubbard AK, Giardina C: Regulation of ICAM-1 expression in mouse macrophages. Inflammation 2000, 24:115-125

51. Tomioka H, Shimizu T, Maw WW, Ogasawara K: Roles of tumour necrosis factor-alpha (TNF-alpha), transforming growth factor-beta (TGF-beta), and IL-10 in the modulation of intercellular adhesion molecule-1 (ICAM-1) expression by macrophages during mycobacterial infection. Clin Exp Immunol 2000, 122:335-342

52. Sakurada S, Kato T, Okamoto T: Induction of cytokines and ICAM-1 by proinflammatory cytokines in primary rheumatoid synovial fibroblasts and inhibition by $\mathrm{N}$-acetyl-L-cysteine and aspirin. Int Immunol 1996, 8:1483-1493

53. Tilghman RW, Hoover RL: E-selectin and ICAM-1 are incorporated into detergent-insoluble membrane domains following clustering in endothelial cells. FEBS Lett 2002, 525:83-87

54. Shaw SK, Ma S, Kim MB, Rao RM, Hartman CU, Froio RM, Yang L, Jones T, Liu Y, Nusrat A, Parkos CA, Luscinskas FW: Coordinated redistribution of leukocyte LFA-1 and endothelial cell ICAM-1 accompany neutrophil transmigration. J Exp Med 2004, 200:1571-1580

55. Carman CV, Springer TA: A transmigratory cup in leukocyte diapedesis both through individual vascular endothelial cells and between them. J Cell Biol 2004, 167:377-388

56. Sumagin R, Sarelius IH: Intercellular adhesion molecule-1 enrichment near tricellular endothelial junctions is preferentially associated with leukocyte transmigration and signals for reorganization of these junctions to accommodate leukocyte passage. J Immunol 2010, 184: $5242-5252$

57. Diamond MS, Staunton DE, Marlin SD, Springer TA: Binding of the integrin Mac-1 (CD11b/CD18) to the third immunoglobulin-like domain of ICAM-1 (CD54) and its regulation by glycosylation. Cell 1991, 65:961-971 